\title{
The Purley train crash mechanism: injuries and prevention
}

N. J. FOTHERGILL, S. R. EBBS, A. REESE,

R. J. PARTRIDGE, M. MOWBRAY,

R. D. C. SOUTHCOTT \& K. HASHEMI

Mayday University Hospital, Mayday Road, Thornton Heath, Surrey

\section{SUMMARY}

On the afternoon of Saturday 4th March 1989 two trains, both bound for London Victoria Station, collided. Part of the rear train rolled down a steep railway embankment and jack-knifed against a tree. The mechanism of the crash and the injuries sustained by the 55 victims who were seen in the A\&E Department of the Mayday University Hospital are described.

Improvements in signalling technology and design of rolling stock which may reduce both the risk of collision and severity of injury in future accidents are discussed.

\section{The crash}

At approximately $13.25 \mathrm{hrs}$ on Saturday 4th March 1989 the $11.47 \mathrm{hrs}$ train from Littlehampton and Portsmouth Harbour collided with the rear end of the $12.50 \mathrm{hrs}$ train from Horsham that was also bound for London Victoria.

The first seven carriages of the Littlehampton train were derailed, five ploughed down the steep railway embankment and partially rolled over. On impact with the tree the first two carriages jack-knifed back (Fig. 1).

Patients from the Littlehampton train described feeling as though they were in the revolving drum of a washing machine, being thrown both forwards in the carriage and against the floor, roof and sides as the train plunged down the embankment. Many people said that they had been injured by the metal and wooden seat frames from which the padding had come off. Some were thrown through the train windows to land beneath the carriage. Many said that they had been hit by unrestrained luggage and other passengers.

Correspondence: Mr K. Hashemi, Consultant Accident and Emergency Department, Mayday University Hospital, Thornton Heath, Surrey CR4 TYE. 


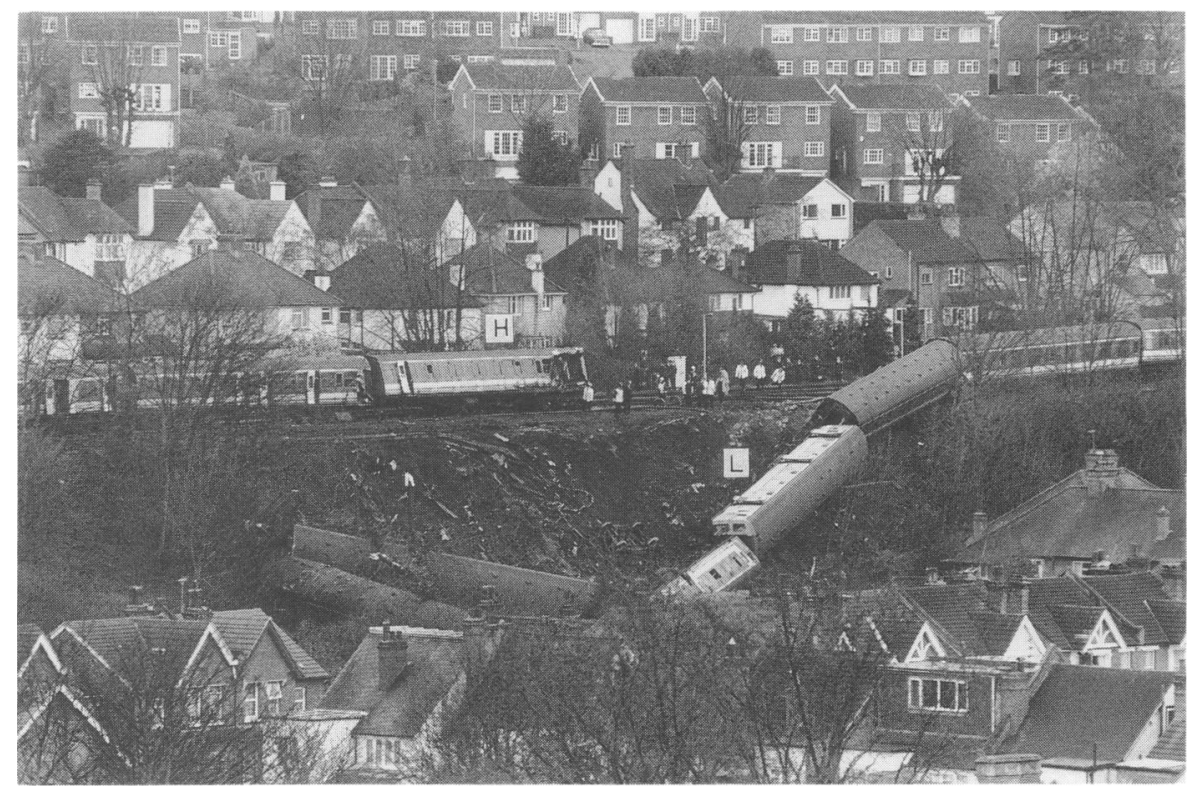

Fig. 1. The scene after the crash (Reproduced with permission of Richard Mildenhall-The Observer). Both trains travelling from right to left. $\mathrm{L}$ is the Littlehampton and Portsmouth Harbour train; and $\mathrm{H}$ is the rear carriage of the Horsham train.

\section{The Accident and Emergency Department}

The first of the 55 casualties from the crash arrived at the A\&E Department at $14.30 \mathrm{hrs}$, and two-thirds had been seen by $15.30 \mathrm{hrs}$. The ages of the patients are shown in Table 1.

The injuries of each patient were scored using the 1985 revision of the Abbreviated Injury Scale (Abbreviated Injury Scale, 1985 revision). Using police records and patient interviews in Hospital after the crash, the positions of all 55 patients in the train prior to impact were determined. The Abbreviated Injury Scores (AIS) of the patients, related to their position in the trains before the crash, are shown in Table 2. Scores over 20 are considered to represent serious injury. Most patients who were seriously injured or killed had been sitting in the carriages which had jackknifed agaist the tree, and almost two-thirds had been in seats facing forwards.

The average AIS of the first 18 patients to arrive in A\&E. was 10, of the second 18 was nine and the AIS of the last 19 patients was eight: that these vary so little reflects the fact that there was no triage at the accident site. Of the 24 patients in whom initial examination time was recorded in the A\&E records, those seen within $30 \mathrm{~min}$ of the first patient's arrival had an average AIS of 16, those seen within $1 \mathrm{~h}$ had an average AIS of nine and those seen after $1 \mathrm{~h}$ had an average AIS of 3, suggesting that effective prioritization was carried out within A\&E. The last patient was seen at $17.00 \mathrm{hrs}$ and the Casualty Department was cleared by $17.30 \mathrm{hrs}$ to resume its normal Saturday night service after the staff had taken a 30 min break. 
Table 1. Ages of patients from crash.

\begin{tabular}{|c|c|c|c|c|}
\hline \multirow[b]{2}{*}{$\begin{array}{l}\text { Age group } \\
\text { years }\end{array}$} & \multicolumn{2}{|c|}{ Men } & \multicolumn{2}{|c|}{ Women } \\
\hline & Admitted & $\begin{array}{l}\text { Discharged } \\
\text { from } A \& E\end{array}$ & Admitted & $\begin{array}{l}\text { Discharged } \\
\text { from A\&E }\end{array}$ \\
\hline Less than 10 & 1 & 2 & 0 & 0 \\
\hline $11-20$ & 2 & 0 & 0 & 0 \\
\hline $21-30$ & 1 & 2 & 2 & 3 \\
\hline $31-40$ & 2 & 5 & 2 & 3 \\
\hline $41-50$ & 3 & 2 & 3 & 1 \\
\hline $51-60$ & $\begin{array}{c}3 \\
\text { (1 died) }\end{array}$ & 3 & 1 & 0 \\
\hline $61-70$ & 1 & 2 & 3 & 0 \\
\hline $71-80$ & 1 & 1 & $\begin{array}{c}2 \\
(1 \text { died })\end{array}$ & 2 \\
\hline Totals & 14 & 17 & 13 & 9 \\
\hline
\end{tabular}

1 male patient was transferred from A\&E to another hospital.

1 male patient died in A\&E

2 patients were dead on arrival at a neighbouring hospital.

Age range, men 4-75 years, women 21-79 years. Mean age, men 41 years, women 47 years.

Table 2. Abbreviated injury score of victims by position in trains.

\begin{tabular}{lcccccc}
\hline Train & Carriage & $\begin{array}{c}\text { Number of } \\
\text { victims }\end{array}$ & $\begin{array}{c}\text { Facing } \\
\text { front }\end{array}$ & $\begin{array}{c}\text { Facing } \\
\text { back }\end{array}$ & $\begin{array}{c}\text { AIS } \\
\text { range }\end{array}$ & $\begin{array}{c}\text { AIS } \\
\text { mean }\end{array}$ \\
\hline $\mathrm{L}$ & 1 & 5 & 4 & 1 & $1-29$ & 10 \\
$\mathrm{~L}$ & 2 & 8 & 6 & 2 & $1-5$ & 2 \\
$\mathrm{~L}$ & 3 & 27 & 15 & 12 & $1-41$ & 10 \\
$\mathrm{~L}$ & 4 & 8 & 6 & 2 & $1-26$ & 13 \\
$\mathrm{~L}$ & 5 & 4 & 2 & 2 & $1-5$ & 3 \\
$\mathrm{H}$ & 1 & 3 & 3 & 0 & $1-10$ & 6 \\
Totals & & 55 & $36(65 \%)$ & $19(35 \%)$ & & \\
\hline
\end{tabular}

L, Littlehampton Portsmouth Harbour train H, Horsham Train

Procedural and communication problems encountered during that afternoon have been discussed elsewhere (Ebbs et al., 1992). In the A\&E Department there was lack of space, but no shortage of skilled medical and nursing staff to cope with the numbers of casualties. Four operating theatres were open and fully staffed to receive patients by $14.30 \mathrm{hrs}$.

\section{The injuries}

The majority of the patients had sustained moderately severe soft tissue injuries with bruising, crushing and lacerations. Injuries to one area of the body, whether single or multiple have been counted as a single injury. Of the 43 lacerations, $72 \%$ were to the scalp or face. There were 35 fractures, of which equal numbers were of 
ribs, spine and upper limbs. There were only two lower limb fractures. Ten patients were knocked unconscious, but only one survivor had a skull fracture.

One patient died soon after arrival in A\&E with severe spinal injuries and two died within $2 \mathrm{~h}$ in the Intensive Care Unit, with multiple injuries including severe head and spinal trauma. The AIS of those who died were 29, 41 and 41 . Two patients were dead on arrival at another local A\&E Department.

\section{Management}

A total of 26 patients were discharged home from the A\&E Department after assessment and treatment of their injuries. Thirteen required suturing, all of which was carried out by nursing staff. All patients were discharged with a letter to take to their GP for re-examination and follow-up. The Social Work Department and Chaplaincy later wrote to all patients, having identified counselling services in the patients' localities, for psychological follow-up as none of the crash victims lived locally. Reaction of Hospital staff to the incident has been described elsewhere (Woodruff, 1989). Twenty-eight patients were admitted for an average of 8 days, excluding one man who is still an in-patient. The AIS of those admitted ranged from 1-41, with a mean of 14 . Three laparotomies and one thoracotomy were undertaken as emergencies and three fractures required subsequent open reduction and internal fixation.

One patient was transferred from the A\&E Department to a neighbouring hospital for specialist assessment of severe spinal injuries and remains paraplegic from T6 due to spinal transection at this level; a 47-year-old woman later spent some time at the Regional Neurosurgical Unit for assessment of her head injury and has a right hemiparesis due to multiple punctate heamorrhages of the left cerebral hemisphere. All other patients were managed at this Hospital.

\section{DISCUSSION}

In Britain a person is roughly 20 times more likely to die as a car passenger than as a train passenger travelling the same distance. From 1950 to 1959 during which time nearly 400 passengers and railway staff died in rail crashes, there was a progressive reduction in rail deaths, until the last decade when just over 100 people died. This fall has been due to the development of better signalling systems and to the design of safer railway carriages. The recent trilogy of train disasters, killing 35 people at Clapham Junction on 12th December, 1988, five at Purley on 4th March and two in Glasgow on 6th March, 1989 have prompted public enquiries and demands for still safer trains (The Economist, 1989).

In any vehicular accident, information on the environment, the victims and the vehicle must be collected, collated and analysed in order to reduce the subsequent risk and when, accidents do occur, to reduce the severity of injuries that the victims sustain (Hashemi, 1989).

The most important environmental factor in the reduction of train crashes is improved signalling; and the currently available new generation technology would 
probably have prevented both the Purley and the Glasgow train crashes, but would cost between $£ 100$ and $£ 200$ million to install in the South Eastern Region alone (The Economist, 1989). About half the accidents that still occur involve driver error, and, as well as improved 'fail safe' signalling, driver training, retraining and comfort in the cab are of paramount importance.

The Civil Aeronautics Institute in Oklahoma has investigated rail crashes in the U.S.A. (Braden, 1974; 1975). Their investigations have shown that deceleration forces alone cause little injury, but fatalities and severe injuries occur particularly in passengers who's carriage jack-knifes or rotates on its long axis, reinforcing our observations of the Purley crash.

From our assessment of the mechanism of the injuries in the Purley crash, improvements in the design of carriage interiors may reduce morbidity and mortality in future accidents. The single most important measure would be the provision of seat-belts for train passengers. Those who were unrestrained during the crash would have been less severely injured if their luggage had been stored in lockers, if the padding had not come off the seats, if fixtures and fittings had been designed with fewer sharp corners and if the carriages had not had large areas of glazed window. These recommendations would be relatively inexpensive to implement, improving the saftey of existing rolling stock.

The rail crash we have reported might have been a disaster on a huge scale had it occurred on a weekday when the trains would have been packed with commuters. The 'crash worthiness' of trains warrants detailed investigation so that improved design may reduce fatality and serious injury in any future accidents.

\section{REFERENCES}

Abbreviated Injury scale (1985) Revision. American Association of Automotive Medicine.

Braden G. (1974) Application of commercial aircraft accident investigation techniques to a railroad derailment. Clinical Aviation and Aerospace Medicine 45(7), 772-779.

Braden G. (1975) Aircraft - type crash injury investigation of a commuter train collision. Aviation, Space and Environmental Medicine 46(9), 1157-1160.

Ebbs S. R., Fothergill N. J. \& Hashemi K. (1992) The Purley train crash: procedural difficulties. Archives of Emergency Medicine 9, 130-133.

The Economist (1989) Train Crashes: how not to shoot the lights March 11.

Hasemi K. (1989) Hazards of the forklift truck. M D Thesis, University of Birmingham.

Woodruff I. (1989) A report on staff reaction at the Mayday University Hosital following the Major Incident of the Purley Train Crash. British Journal of Accident and Emergency Medicine 4(2), 4-5. 